\title{
Association between Cerebral Shape and Social Use of Language in Williams Syndrome
}

\author{
Doron Gothelf ${ }^{*}, 1,2$, Yvonne M. Searcy ${ }^{3}$, Judy Reilly ${ }^{4}$, Philip Lai ${ }^{4}$, Tope Lanre-Amos ${ }^{7}$, Debra \\ Mills $^{3}$, Julie R Korenberg ${ }^{5}$, Albert Galaburda ${ }^{6}$, Ursula Bellugi ${ }^{3}$, and Allan L Reiss ${ }^{7}$ \\ ${ }^{1}$ Behavioral Neurogenetics Center, Department of Child Psychiatry, Schneider Children's, \\ Medical Center of Israel, Petah Tiqwa, Israel \\ ${ }^{2}$ Sackler Faculty of Medicine, Tel Aviv University, Ramat Aviv, Israel \\ ${ }^{3}$ The Salk Institute for Biological Studies, La Jolla, CA \\ ${ }^{4}$ San Diego State University and Université de Poitiers-CNRS, France \\ ${ }^{5}$ Cedars-Sinai Medical Center, Medical Genetics Institute, Division of Neurogenetics and UCLA \\ Departments of Human Genetics and Pediatrics \\ ${ }^{6}$ Beth-Israel Deaconess Medical Center and Harvard Medical School, Boston, MA \\ ${ }^{7}$ Center for Interdisciplinary Brain Sciences Research, Department of Psychiatry and Behavioral \\ Sciences, Stanford University School of Medicine, Stanford, CA
}

\section{Abstract}

Williams syndrome is a neurogenetic disorder resulting from a hemizygous microdeletion at band 7q11.23. It is characterized by aberrant development of the brain and a unique profile of cognitive and behavioral features. We sought to identify the neuroanatomical abnormalities that are most strongly associated with Williams syndrome employing signal detection methodology. Once identified with a Quality Receiver Operating Characteristic Curve, we hypothesized those brain regions distinguishing subjects with Williams syndrome from controls would be linked to the social phenotype of individuals with this disorder. Thirty-nine adolescents and young adults with Williams syndrome and 40 typically developing controls matched for age and gender were studied. The Quality Receiver Operating Characteristic Curve identified a combination of an enlarged ventral anterior prefrontal cortex and large bending angle of the corpus callosum to distinguish between Williams syndrome and controls with a sensitivity of $85.4 \%$ and specificity of $75.0 \%$. Within the Williams syndrome group, bending angle significantly correlated with ventral anterior prefrontal cortex size but not with other morphometric brain measures. Ventral anterior prefrontal size in subjects with Williams syndrome was positively associated with the use of social engagement devices in a narrative task assessing the use of social and affective language. Our findings suggest that aberrant morphology of the ventral anterior prefrontal cortex is a pivotal contributing factor to the abnormal size and shape of the cerebral cortex and to the social-affective language use typical of individuals with Williams Syndrome.

\section{Keywords}

Williams Syndrome; social cognition; cortex; shape; language; ventral prefrontal

\footnotetext{
*Corresponding author: Doron Gothelf, M.D., Child Psychiatry Department, Schneider Children's Medical Center of Israel, 14 Kaplan St., Petah Tiqwa 49202, Israel. Tel: +972-3-922-7415; Fax: +972-3-925-3864; Email: gothelf@ post.tau.ac.il
} 


\section{INTRODUCTION}

Williams syndrome (WS) is caused by a $\sim 1.6 \mathrm{Mb}$ chromosomal microdeletion at band 7q11.23 (Bayes et al., 2003). The microdeleted region consists of $\sim 28$ genes. The estimated incidence of WS is up to 1 in 7500 live births (Stromme et al., 2002). The syndrome is a multisystem disorder manifested by a wide range of medical disorders (Pediatrics, 2001) and the majority of people with WS have cognitive deficits, with IQ's typically in the mild to moderate range of mental retardation.

\section{Neuroanatomical Profile of WS}

Social behavior in WS may involve interaction of several factors including social cognition and social desire, regulation of emotions and disinhibition [Bellugi et al., 2007; Porter et al., 2007]. Two key brain networks are putatively involved in shaping social behavior. The first is the ventral circuit monitoring social cognition that includes the amygdala, anterior cingulate, superior temporal gyrus (STG) and mediodorsal nucleus of the thalamus [Adolphs, 2001; Bachevalier and Loveland, 2006]. The amygdala processes multimodal sensory information and retrieves socially relevant knowledge by analyzing the emotions of facial expressions [Adolphs, 2001; Bachevalier and Loveland, 2006]. The social information processed in the amygdala is transferred to the orbitofrontal cortex where social responses and behaviors are selected [Adolphs, 2001]. The second brain network regulating social behavior is the striatal-thalamocrtical loop. This network is in charge of behavioral inhibition and includes prefrontal regions- the orbital and lateral cortices and anterior cingulate [Middleton and Strick, 2002].

Research accumulated in recent years has begun to delineate the neuroanatomical abnormalities occurring in individuals with WS. Overall brain volume in WS is decreased by about $10 \%$, which is particularly attributable to reductions in parietal and occipital lobe volumes [Meyer-Lindenberg et al., 2004; Reiss et al., 2004]. Regions that are relatively increased in gray matter volume in WS include the ventral prefrontal cortex, STG, amygdala and posterior vermis of the cerebellum [Meyer-Lindenberg et al., 2004; Reiss et al., 2004; Reiss et al., 2000; Schmitt et al., 2001a; Schmitt et al., 2001b]. In addition to volumetric abnormalities, the shape of the cerebrum is different in WS. The decreased parieto-occipital lobe volumes relative to frontal volumes are thought to lead to a more flat bending angle of the corpus callosum and cerebrum in WS compared to typical controls [Schmitt et al., 2001a].

\section{The Social Phenotype}

People with WS are often described as being 'overly friendly' and 'gregarious' showing enhanced social interest in others, hypersensitivity to others' feelings, and a strong affiliative drive. Yet they have pronounced difficulties in making friendships [Doyle et al., 2004; Jones et al., 2000; Mervis and Klein-Tasman, 2000]. An increased interest in social interactions is one of the most salient phenotypic features of the syndrome that is evident from infancy and extends into adulthood [Davies et al., 1998; Jones et al., 2000; Meyer-Lindenberg et al., 2006]. The gregariousness of individuals with WS is accompanied by social disinhibition even towards people they objectively do not consider approachable [Frigerio et al., 2006].

\section{Social Use of Language in WS}

Language abilities in WS are sharply bifurcated. The grammatical proficiency is significantly impaired in individuals with WS and commensurate to the cognitive deficits associated with the syndrome. Social use of language is unique in individuals with the syndrome [Bellugi et al., 2000]. Language can be analyzed at the level of grammatical proficiency or alternatively in terms of the use of language in discourse and narrative. Reilly 
et al., [2004] investigated the development of grammatical mastery and the social use of language in children with WS, using narratives as a context, they coded for grammatical complexity and correctness. To control for length, proportions were created using the total number of clauses as the denominator (see Methods section). Children with WS syndrome were found to produce many fewer grammatically correct clauses than normal controls, reflecting their grammatical deficiencies. The same narratives were also coded for the use of social evaluative language. Social evaluative language refers to lexically conveyed affect and sociability, or language that reflects the narrator's attitude or perspective. Evaluative devices are linguistic tools used to attribute emotions or motivations to characters in the story, build suspense, and maintain audience involvement and interest [Berman and Slobin, 1994]. Examples include: emphatics, intensifiers (e.g., really, very and so), character speech, direct quotes and sound effects. An added category of evaluative devices termed "audience hookers", defined as devices to capture and maintain the listener's attention, was developed to characterize language functions salient in WS. Using Reilly Evaluation Coding System (RECS) [Reilly et al., 1998], it was found that in contrast to their grammatical performance, the WS group used significantly more evaluative language than controls [Bellugi et al., 2007; Losh et al., 2000; Reilly et al., 2004] (see Fig. 1 a \& b). Thus, in WS there is a sharp bifurcation between proficiency with linguistic structure (mastery of morpho-syntax) and the social affective use of language (evaluation).

The excessive use of social affective language in WS compared to other groups has now been shown in a series of studies:

a. Excessive evaluative language has been identified across different ages in WS from childhood through late adolescence [Losh et al., 2000; Reilly et al., 1990; Reilly et al., 2004].

b. Abnormal social evaluation seems specific to WS. WS exhibit significantly higher use of social language in comparison to normal controls and other neurodevelopmental disorders (individuals with focal brain lesions, language impairment and high functioning autism [Järvinen-Pasley et al., 2007, in press; Reilly et al., 2004] (see Fig. 1c)

c. Excessive social language is characteristic of WS in other discourse genres compared to other groups, not only in narratives, but also in picture description, biographical interviews and dyadic conversation [Bellugi et al., 1999].

d. Evaluative language is significantly higher in WS than controls across different languages and widely different cultures (France, Italy, USA), indicating the genetic predisposition for social affiliation in WS [Reilly et al., 2005a; Reilly et al., 2005b; Zitzer-Comfort et al., 2007, in press] (see Fig. 1d).

\section{Summary}

The purpose of the present study was to advance our understanding of the relation between neuroanatomical abnormalities and hypersocial behavior in WS. Since a wide variety of brain regions are aberrant in WS, it is difficult to know which of these regions are most strongly associated with particular aspects of the cognitive and behavioral phenotype. We decided to focus on the use of atypical social and affective language in WS, as this is a salient and replicable phenotypic characteristic of the syndrome. We predicted that brain regions that most sensitively and specifically distinguish individuals with WS from controls would also significantly correlate with this aspect of the social phenotype. To test this hypothesis, we first employed signal detection method to identify those brain regions that are most strongly associated with WS, and then we evaluated the association of these regions with a specific measure of social use of language. 


\section{MATERIAL AND METHODS}

\section{Sample}

Participants included 39 young adults with WS and 40 age and gender matched typically developing controls. The clinical characteristics of the study sample are presented in Table 1. All participants with WS were recruited and evaluated at the Salk Institute as part of a comprehensive multi-disciplinary research program project (HD 330113). Controls were recruited at both the Salk Institute and Stanford University. Participants with WS were confirmed to have a deletion of chromosome 7q11.23 that included the elastin gene, using multicolor fluorescence in situ hybridization and met diagnostic criteria for WS based on phenotypic features according to the WS Diagnostic Score Sheet [Pediatrics, 2001]. IQ was assessed in 37 of 39 individuals with WS using the Wechsler Adult Intelligence Scale Revised (WAIS-R) [Wechsler, 1997].

The typically developing control subjects had no history of major psychiatric, neurological, or cognitive impairment. All behavioral data were acquired within one year from scan acquisition time. The institutional review boards of both Stanford University and Salk Institute approved the research protocols. All participants and, if appropriate, their parents or guardians provided informed written consent for the study.

Image acquisition and processing-All participants were scanned with a General Electric 1.5 Tesla Signa Scanner (GE Imaging Systems, Milwaukee, WI) located at one of three sites: University of California, San Diego Medical Center Magnetic Resonance Imaging Institute; Scripps Clinic, San Diego; or Stanford University as previously described [Reiss et al. 2004]. In all cases, sagittal brain images were acquired with the same threedimensional (3D) volumetric radio frequency spoiled gradient echo pulse sequence using the following scan parameters: repetition time, $24 \mathrm{~ms}$; echo time, $6 \mathrm{~ms}$; flip angle, $45^{\circ}$; slice thickness, $1.2 \mathrm{~mm}$; field of view, $24 \mathrm{~cm}$; and matrix size, $256 \times 192$ for 124 contiguous slices. Data processing steps were conducted following a well-established protocol [Reiss et al., 1998]) included removal of non-brain tissues from the images, correction of equipment related image artifacts, and separation (segmentation) of tissue components (grey, white, CSF).

Volumetric measures-Each brain was positionally normalized to make it parallel to the plane defined by the anterior and the posterior commissures. The brain tissue was subdivided based on Talairach parcellation method into the four cerebral lobes, subcortex and brainstem on the basis of stereotaxic atlas template [Kates et al., 1999; Reiss et al., 1998; Talairach and Tournoux, 1988]. The cerebellum was manually segmented.

Four subregions of prefrontal grey matter (dorsal, mid-superior, mid-inferior, and ventralanterior) were obtained using previously described methods [Reiss et al., 2004;

Schoenemann et al., 2005]. Briefly, the prefrontal cortex was defined as all frontal cortical grey matter lying anterior to a coronal plane intersecting the most anterior point of the genu of the corpus callosum [Schoenemann et al., 2005]. The inferior subdivision of the prefrontal parcellation corresponds to the ventral anterior prefrontal cortex (VAPFC, Fig. 2a). In a similar manner, the cingulate gyrus was subdivided into four components corresponding to inferior, dorsal-anterior, middle, and posterior segments [Reiss et al., 2004].

Trained research assistants, following detailed protocols, delineated additional regions of interest (ROI) volumes manually. The ROI variables included the volumes of the hippocampus and amygdala [Kates et al., 1997], thalamus [Chang et al., 2005] the grey matter volume of the superior temporal gyrus [Kesler et al., 2003], and the bending angle of 
the corpus callosum [Schmitt, 2001a] (Fig. 2b). Raters were blind to subject diagnosis, gender, and other subject characteristics; inter-rater reliabilities for volumes of manually drawn ROIs were above 0.90 as calculated by the intraclass correlation coefficient.

Social Use of Language-Twenty-five participants with WS (11 females, 14 males, mean age $29.3 \pm 9.5$ and mean FSIQ $69.8 \pm 7.1$ ) completed an assessment of social cognition using a narrative task that has been previously used and described in studies of individuals with WS [Losh et al., 2000; Reilly et al., 1990; Reilly et al., 2004]. There is no overlap between the subjects evaluated for language in the current study and previous reports on language in WS. In this narrative task, subjects are presented with the 24-page wordless picture book "Frog, where are you?" [Mayer, 1969], and asked to tell the story to the experimenter. The narrations were video- and audio-taped; they were then transcribed, according to the Child Language Data Exchange System (CHILDES), a system that transcribe the oral stories of participants to written transcriptions [MacWhinney, 2000].

The stories were then coded using the coding scheme which was designed to assess both grammatical proficiency, and use of evaluative language [Reilly et al., 1998]. Stories were first coded for length as measured by number of propositions; a proposition is defined as a verb and its arguments; semantically, a proposition corresponds roughly to a single event. Each clause in a complex sentence was considered to represent one event, and therefore, one proposition. To control for varying story lengths, the number of propositions in a story was used as a denominator for the additional analyses. Morphological errors were tallied and categorized by type as were the frequency and types of complex syntax recruited. Proportions were created for all measures. Transcription and coding was conducted by two independent trained researchers and reliability was at or above $90 \%$.

For this project we were especially interested in the use of social evaluative language. Evaluative language is defined as elements within the story that convey the narrator's perspective on events [Labov and Waletzky, 1967]. One type of evaluative language is social engagement devices (SED); these include phrases that add interest, serving to attract and maintain the listener's attention, e.g. sound effects, intensifiers, very, so and character speech, such as, "The boy said, 'Oh, little froooggie, where have you gone?'”. Additional evaluative devices include inferences about characters and events, character motivation, and the narrator's level of certainty concerning events. According to Labov's definition, all stories include evaluation. In this study, we were particularly interested in the degree to which the WS participants used social versus other types of evaluative devices. Thus, each participant received proportion score (SED), which was calculated by dividing the number of social evaluations by the total number of evaluative devices.

\section{The Quality Receiver Operating Characteristic Curve (QROC) analysis-The} QROC [Gothelf et al., 2008; Kiernan et al., 2001; Kraemer, 1992; O'Hara et al., 2002; Salmond et al., 2002] version 4.19 (http://mirecc.stanford.edu) was applied to identify the brain regions that most sensitively and specifically distinguished subjects with WS from controls. For this analysis we included brain regions that have been reported by our group or others to be abnormal in subjects with WS [Meyer-Lindenberg et al., 2004; MeyerLindenberg et al., 2005b; Reiss et al., 2004; Schmitt et al., 2001a; Schmitt et al., 2001b]. The gray matter volumes of the following regions were included in the QROC analysis: ventral and dorsal anterior prefrontal regions, dorsal-anterior cingulate, parietal and occipital lobes, superior temporal gyrus, cerebellum, amygdala, hippocampus, and thalamus. The bending angle of the corpus callosum also was included [Schmidt et al., 2001a].

These brain measures were entered as independent variables, and the binary outcome measure was group status (WS vs. controls). To statistically account for the smaller overall 
brain size of subjects with WS, all brain variables entered into the analysis, besides the bending angle, were adjusted using linear regression, with total cerebral tissue as the independent variable, and each of the brain regions as the dependent variable. The unstandardized residual value of each region derived from these analyses was then entered into the QROC. The QROC searched all independent variables, values representing adjusted brain volumes and their associated cutpoints, and identified those that had the optimal balance between sensitivity and specificity for distinguishing between WS and controls. Once the optimal variable and associated cutpoints were identified, the strength of the cutpoint for the chosen variable was compared to the random probability by using a stopping rule of a $P<0.001$ in a $2 \times 2$ chi-square test. If the variable passed this "test", the sample was divided into two subgroups, above and below the cutpoint. The QROC analysis was then restarted, independently, for each of these two subgroups. The procedure again examined every remaining variable and associated cutpoints to see if either group could be further differentiated. The resulting outputs were given as a decision tree (see Fig 3). The QROC procedure stopped when it hit the stopping rule, and/or when a subgroup was too small for further analysis [Kiernan et al., 2001;Kraemer, 1992;O'Hara et al., 2002;Salmond et al., 2002].

\section{RESULTS}

\section{Brain regions that distinguish Williams syndrome}

As illustrated in Figure 3, from a total of 79 subjects, 39 (49.4\%) had WS and 40 (51.6\%) were controls. At the first level of the QROC, the adjusted grey matter volume of the VAPFC was identified as the most optimal variable that distinguished between WS and controls, with a cut point of $22.76 \mathrm{~cm}^{3}$. Of the 33 subjects with VAPFC $\geq 22.76,27(81.8 \%)$ were from the WS group; whereas of the 46 subjects with VAPFC $<22.76$ only $12(26.1 \%)$ had WS. Alternatively, 27 of 39 subjects with WS (69.2\%) and only 6 of 40 TD controls $(15.0 \%)$ had large VAPFC. A univariate analysis of covariance (ANCOVA) with VAPFC as the dependent variable, group (WS vs. controls) as fixed factor and total cranial tissue as a covariate confirmed a robust difference in VAPC volumes between groups $(25.6 \mathrm{cc} \pm 5.1 \mathrm{cc}$ for WS vs. $17.1 \pm 4.6$ for controls, $\mathrm{t}=5.6, P<0.0001$, effect size $=1.8$ ).

Among those with VAFC $<22.76$ (left side of Figure 3), the next optimal variable to divide the sample was the bending angle, with a cutpoint of $109^{\circ}$. The end result of the QROC partition yielded three groups: (1) VAPFC $\geq 22.76 \mathrm{~cm}^{3}, 81.8 \%$ of whom were from the WS group; (2) VAPFC $<22.76 \mathrm{~cm}^{3}$ and bending angle $\geq 109^{0}, 60.0 \%$ with WS; (3) VAPFC < $22.76 \mathrm{~cm}^{3}$ and bending angle $<109^{0}$, only $16.7 \%$ with WS. The combination of large VAPFC or small VAPFC and large bending angle had $85.4 \%$ sensitivity and $75.0 \%$ specificity in distinguishing WS from controls.

\section{Social Use of Language}

In this study, we investigated the extent to which the WS participants used social versus other types of evaluative devices. Each participant received a score reflecting the proportion of SED to the total evaluation score. The mean SED score of the WS group was $0.62 \pm 0.17$, with no gender differences $(t=0.96, P=0.34)$. To contextualize these results, we also coded Frog story narratives from additional sample of 40 TD young adults also recruited from the area of Salk Institute and Stanford University. The TD controls were matched for age (27.6 \pm 7.2 years) and gender ( 20 males and 20 females) to the WS group. As is typical of narratives, both populations used significant amounts of evaluations in their stories. However, the two groups differed in the distribution of social versus other types of evaluation. As seen in Figure 4, the proportion of SED was significantly higher in the WS 
group $(0.61 \pm 0.17)$ than in the TD control group $(0.31 \pm 0.10, \mathrm{t}=8.0, P<.0001$, effect size $=2.2$ ).

\section{Association analyses of cerebral shape}

The QROC identified enlarged VAPFC and bending angle of the corpus callosum as key components of the morphological brain phenotype in WS. As flattening of the bending angle in WS may be secondary to focal changes in both anterior and posterior parts of the brain, we tested the hypothesis that the bending angle variable would be significantly correlated with other morphological measures used in this study. In particular, since morphology of both the VAPFC and parieto-occipital cortex are abnormal in WS [Meyer-Lindenberg et al., 2004; Reiss et al., 2004], both brain regions potentially contribute to the flattening of the bending angle. Bending angle was significantly correlated with VAPFC $(r=0.36, P<0.05)$, but not with occipital $(r=-0.17, P=0.28)$, nor with parietal $(r=0.29, P=0.07)$ lobe volumes. In the control group there were no significant correlations between the bending angle and any of these three measures $(P$ 's $>0.1)$.

\section{Association between social evaluation device scores and VAPFC size}

To test the hypothesis that the VAPFC would be associated with the social phenotype of WS, specifically use of social evaluative language, we compared SED scores of the WS subgroup with large VAPFC $\left(\geq 22.76 \mathrm{~cm}^{3}, \mathrm{n}=17\right)$ and the WS subgroup with small VAPFC $\left(<22.76 \mathrm{~cm}^{3}, n=8\right)$. The subgroup with large VAPFC had significantly higher SED scores than the subgroup with small VAPFC $(0.67 \pm 0.16$ vs. $0.50 \pm 0.15, t=-2.5, P<$ 0.05 , effect size $=1.1$,). There was also a significant positive medium to large correlation between adjusted VAPFC volume and SED scores of the WS group $(r=0.50, P<0.01)$.

To evaluate whether, in addition to VAPFC, other brain regions significantly contributed to the variability of SED scores in the WS group, we conducted a linear regression with several brain regions chosen as predictors based on the literature indicating the importance of these regions for social regulation [Adolphs, 2001; Bachevalier and Loveland, 2006]. The brain regions chosen were the adjusted volumes of the amygdala and STG, in addition to adjusted VAPFC volume. FSIQ scores were entered as additional predictor. Only adjusted VAPFC volume significantly predicted SED scores $(\beta=0.50, P=0.03)$, whereas amygdala volume $(\beta=-0.17, P=0.42)$, STG volume $(\beta=0.11, P=0.53)$ and FSIQ scores $((\beta=0.03, P=$ 0.90) did not.

\section{DISCUSSION}

Using QROC analysis, we identified the VAPFC and bending angle of the corpus callosum as measures that distinguish individuals with WS from typically developing controls with moderately high sensitivity and specificity ( $85.4 \%$ and $75.0 \%$, respectively). We also showed that a unique aspect of WS social phenotype, the use of enhanced social language, positively correlates with the size of the VAPFC in WS.

The data presented here are in line with previous studies of brain morphology in WS using a variety of image analysis methods. Results from these studies indicate the existence of aberrant cortical morphology and shape in individuals with WS including increased gyrification [Gaser et al., 2006], increased cortical thickness [Thompson et al., 2005], and folding abnormalities [Van Essen et al., 2006]. Interestingly the VAPFC region is among the most prominent morphological abnormalities emerging from brain imaging studies focused on WS [Gaser et al., 2006; Meyer-Lindenberg et al., 2004; Reiss et al., 2004; Van Essen et al., 2006]. 
In a previous study, it was found that the bending angle of the corpus callosum is larger (flatter) in WS compared to typically developing controls [Schmitt et al., 2001a]. In the present study we found a significant association between the bending angle of the corpus callosum and VAPFC volume, but not with other morphological measures. It is possible, however, that we would have detected other significant correlations if more fine-grained measures of posterior brain morphology were available. The association between the bending angle and VAPFC suggests that aberrant development of the most anterior parts of the cortex contributes to abnormal bending of the cerebrum in WS as well as to prominence of the VAPFC cortical region as defined in the present study.

Overall, the cerebral cortex of individuals with WS is reduced in size in its posterior pole and increased in size in its anterior pole. There is increasing evidence that anterior-posterior patterning of cortical development is determined by differential gene expression [Grove and Fukuchi-Shimogori, 2003]. Haploinsufficiency of one or several genes that are within the WS deletion region may result in the observed unbalanced development of the cerebral cortex of affected individuals. One such candidate gene is the FZD9, related to the WNT gene family, which are involved in the anterior/posterior patterning of the cortex.

The QROC analysis indicated that the VAPFC is a strong distinguishing characteristic of individuals with WS. Abnormal morphology and function of the orbitofrontal cortex in WS has been identified in several brain imaging studies [Meyer-Lindenberg et al., 2005a; Meyer-Lindenberg et al., 2004; Van Essen et al., 2006]. The orbitofrontal cortex, which partially overlaps with the VAPFC region defined here, is a pivotal part of the ventral circuit that monitors social cognition and regulates emotional states and behavior [Bachevalier and Loveland, 2006].

Interestingly, we found that the volume of the VAPFC was positively associated with the use of social language of individuals with WS, but not with general cognitive functioning (IQ scores). Somewhat surprisingly, the amygdala and STG regions were not identified by the QROC as strongly distinguishing between WS and controls. Furthermore, it was also only the VAPFC and not the volume of the amygdala or STG that was significantly associated with the abnormal use of social language in individuals with WS.

Social behavior in WS is characterized by a strong drive towards social interaction. Social drive is regulated by prefrontal regions and in particular by the medial OFC (Roberts et al., 2004). Cognitive studies of WS suggest that social behavior of individuals with WS is similar to that of patients with acquired frontal lobe injuries [Porter et al., 2007]. Like patients with acquired frontal lobe injuries there seems to be dissociation in WS between 'knowing' and 'doing' in the social domain. For example, both WS and frontal-injured patients know that strangers should not be approached but yet indiscriminately approach strangers [Porter et al., 2007]. We believe that the dissociation in WS between 'knowing' and 'doing' in social contexts is attributed to their deficits in inhibitory capacity.

Frontostriatal dysfunction during response inhibition in WS was recently reported [Mobbs et al., 2007]. Disinhibition in WS is also consistent with abnormal development of the orbitofrontal cortex that partially overlaps with the VAPFC region defined here. Thus, our results associating VAPFC volume with social use of language in WS provide further support for the important role of prefrontal cortex abnormalities in shaping the social phenotype of WS.

In the present study we utilized a signal detection method (QROC) that has rarely been used in imaging studies. As this study shows, QROC was instrumental in the identification of specific brain measures that are most closely associated with WS. This was especially important since in WS there are a myriad of structural changes in the brain. Using the 
QROC we were able to identify the VAPFC, and consequently to elucidate its association with the use of social language in WS. The QROC also addresses limitations of traditional parametric statistical analyses commonly used in analyzing brain-imaging data. For example, using logistic regression for analysis of brain imaging data does not allow for identifying higher order interactions and does not provide cutpoints for determining sensitivity and specificity [Kiernan et al., 2001]. As such, QROC should be considered as a potentially useful tool in future neuroimaging studies.

Our findings raise the possibility that aberrant neurodevelopment of the ventral anterior region of the prefrontal cortex is an important factor contributing to the unique cerebral morphology of individuals with WS, as a consequence of haploinsufficiency of genes from the deleted region. The results of the present study also suggest that the abnormal morphology of the VAPFC may be associated with the hypersocial language of individuals with WS. However, we cannot conclude from our data if the association between VAPFC size and social language is specific to WS, or also occurs in TD subjects and other group of patients.

\section{Limitations}

Because the VAPFC measure in our study was derived from an atlas-based parcellation using dividing planes, the size of this brain region is likely to reflect cortical shape characteristics as well as actual volume. The VAPC is comprised mainly of the OFC, but includes also the gyrus rectus and small portion of the inferior frontal cortex. Future brainbehavior studies should focus on the structure and function of sub-components of this region, including the gyrus rectus and orbitofrontal cortex, and their association with measures of social cognition, emotion and behavior.

The association between VAPFC volume and SED scores identified in our study was relatively robust and VAPFC volume predicted $28 \%$ of SED scores. However, it should be acknowledged that the multiple statistical testing employed in our study is a limitation and results should be replicated in future studies. Of note, the SED scale used has yet no standard norms. Additional limitation of the present study is the comparison group which included typically developing subjects and not matched IQ subjects.

\section{Acknowledgments}

This study was supported by the National Institute of Health (Grant Nos. MH01142, MH50047, HD31715, and HD40761 to ALR and the Program Project HD33113 "Williams syndrome: Linking Cognition, Brain and Genes" to UB, JRK, DM, AG, \& ALR). [Doyle et al., 2004]

\section{REFERENCES}

Adolphs R. The neurobiology of social cognition. Curr Opin Neurobiol. 2001; 11:231-239. [PubMed: 11301245]

Bachevalier J, Loveland KA. The orbitofrontal-amygdala circuit and self-regulation of socialemotional behavior in autism. Neurosci Biobehav Rev. 2006; 30:97-117. [PubMed: 16157377]

Bayes M, Magano LF, Rivera N, Flores R, Perez Jurado LA. Mutational mechanisms of WilliamsBeuren syndrome deletions. Am J Hum Genet. 2003; 73:131-151. [PubMed: 12796854]

Bellugi U, Adolphs R, Cassady C, Chiles M. Towards the neural basis for hypersociability in a genetic syndrome. Neuroreport. 1999; 10:1653-1657. [PubMed: 10501552]

Bellugi U, Jarvinen-Pasley A, Doyle TF, Reilly J, Reiss AL, Korenberg JR. Affect, social behavior and the brain in Williams syndrome. Current Directions in Psychological Science. 2007; 16:99-104.

Bellugi U, Lichtenberger L, Jones W, Lai Z, St George M. I. The neurocognitive profile of Williams Syndrome: a complex pattern of strengths and weaknesses. J Cogn Neurosci. 2000; 12(Suppl 1):729. [PubMed: 10953231] 
Berman, R.; Slobin, DI., editors. Filtering and packaging narratives. Erlbaum; Hillsdale, NJ: 1994.

Chang K, Karchemskiy A, Barnea-Goraly N, Garrett A, Simeonova DI, Reiss A. Reduced amygdalar gray matter volume in familial pediatric bipolar disorder. J Am Acad Child Adolesc Psychiatry. 2005; 44:565-573. [PubMed: 15908839]

Davies M, Udwin O, Howlin P. Adults with Williams syndrome. Preliminary study of social, emotional and behavioural difficulties. Br J Psychiatry. 1998; 172:273-276. [PubMed: 9614479]

Doyle TF, Bellugi U, Korenberg JR, Graham J. "Everybody in the world is my friend" hypersociability in young children with Williams syndrome. Am J Med Genet A. 2004; 124:263273. [PubMed: 14708099]

Frigerio E, Burt DM, Gagliardi C, Cioffi G, Martelli S, Perrett DI, Borgatti R. Is everybody always my friend? Perception of approachability in Williams syndrome. Neuropsychologia. 2006; 44:254259. [PubMed: 16005478]

Gaser C, Luders E, Thompson PM, Lee AD, Dutton RA, Geaga JA, Hayashi KM, Bellugi U, Galaburda AM, Korenberg JR, Mills DL, Toga AW, Reiss AL. Increased local gyrification mapped in Williams syndrome. Neuroimage. 2006; 33:46-54. [PubMed: 16901723]

Gothelf D, Furfaro JA, Hoeft F, Eckert MA, Hall SS, O'Hara R, Erba HW, Ringel J, Hayashi KM, Patnaik S, Golianu B, Kraemer HC, Thompson PM, Piven J, Reiss AL. Neuroanatomy of fragile X syndrome is associated with aberrant behavior and the fragile $\mathrm{X}$ mental retardation protein (FMRP). Ann Neurol. 2008; 63:40-51. [PubMed: 17932962]

Grove EA, Fukuchi-Shimogori T. Generating the cerebral cortical area map. Annu Rev Neurosci. 2003; 26:355-380. [PubMed: 14527269]

Järvinen-Pasley A, Bellugi U, Reilly J, Reiss AL, Korenberg JR. Defining the social phenotype in Williams Syndrome: A model for linking gene, brain, and cognition. Dev Psychopathol. 2008; 20:1-35. [PubMed: 18211726]

Jones W, Bellugi U, Lai Z, Chiles M, Reilly J, Lincoln A, Adolphs R. II. Hypersociability in Williams Syndrome. J Cogn Neurosci. 2000; 12(Suppl 1):30-46. [PubMed: 10953232]

Kates WR, Abrams MT, Kaufmann WE, Breiter SN, Reiss AL. Reliability and validity of MRI measurement of the amygdala and hippocampus in children with fragile X syndrome. Psychiatry Res. 1997; 75:31-48. [PubMed: 9287372]

Kates WR, Warsofsky IS, Patwardhan A, Abrams MT, Liu AM, Naidu S, Kaufmann WE, Reiss AL. Automated Talairach atlas-based parcellation and measurement of cerebral lobes in children. Psychiatry Res. 1999; 91:11-30. [PubMed: 10496689]

Kesler SR, Blasey CM, Brown WE, Yankowitz J, Zeng SM, Bender BG, Reiss AL. Effects of Xmonosomy and $\mathrm{X}$-linked imprinting on superior temporal gyrus morphology in Turner syndrome. Biol Psychiatry. 2003; 54:636-646. [PubMed: 13129659]

Kiernan M, Kraemer HC, Winkleby MA, King AC, Taylor CB. Do logistic regression and signal detection identify different subgroups at risk? Implications for the design of tailored interventions. Psychol Methods. 2001; 6:35-48. [PubMed: 11285811]

Kraemer, HC. Evaluating medical tests: objective and quantitative guidelines. Sage Publications; Newbury Park, CA: 1992.

Labov, W.; Waletzky, J. Narrative analysis: oral versions of personal experience. Helm, J., editor. University of Washington Press; Seattle: 1967.

Losh M, Bellugi U, Reilly J, Anderson D. Narrative as a social engagement tool: The excessive use of evaluation in narratives from children with Williams syndrome. Narrative Inquiry. 2000; 10:265290.

MacWhinney, B. The CHILDES Project: Tools for Analyzing Talk, Transaction Format and Programs. Lawrence Erlbaum; Mahway, NJ: 2000.

Mayer, M. Frog, where are you?. Dial Press; New York: 1969.

Mervis CB, Klein-Tasman BP. Williams syndrome: cognition, personality, and adaptive behavior. Ment Retard Dev Disabil Res Rev. 2000; 6:148-158. [PubMed: 10899809]

Meyer-Lindenberg A, Hariri AR, Munoz KE, Mervis CB, Mattay VS, Morris CA, Berman KF. Neural correlates of genetically abnormal social cognition in Williams syndrome. Nat Neurosci. 2005a; 8:991-993. [PubMed: 16007084] 
Meyer-Lindenberg A, Kohn P, Mervis CB, Kippenhan JS, Olsen RK, Morris CA, Berman KF. Neural basis of genetically determined visuospatial construction deficit in Williams syndrome. Neuron. 2004; 43:623-631. [PubMed: 15339645]

Meyer-Lindenberg A, Mervis CB, Berman KF. Neural mechanisms in Williams syndrome: a unique window to genetic influences on cognition and behaviour. Nat Rev Neurosci. 2006; 7:380-393. [PubMed: 16760918]

Meyer-Lindenberg A, Mervis CB, Sarpal D, Koch P, Steele S, Kohn P, Marenco S, Morris CA, Das S, Kippenhan S, Mattay VS, Weinberger DR, Berman KF. Functional, structural, and metabolic abnormalities of the hippocampal formation in Williams syndrome. J Clin Invest. 2005b; 115:1888-1895. [PubMed: 15951840]

Middleton FA, Strick PL. Basal-ganglia 'projections' to the prefrontal cortex of the primate. Cereb Cortex. 2002; 12:926-935. [PubMed: 12183392]

Mobbs D, Eckert MA, Mills D, Korenberg J, Bellugi U, Galaburda AM, Reiss AL. Frontostriatal dysfunction during response inhibition in Williams syndrome. Biol Psychiatry. 2007; 62:256-261. [PubMed: 16996488]

O’Hara R, Thompson JM, Kraemer HC, Fenn C, Taylor JL, Ross L, Yesavage JA, Bailey AM, Tinklenberg JR. Which Alzheimer patients are at risk for rapid cognitive decline? J Geriatr Psychiatry Neurol. 2002; 15:233-238. [PubMed: 12489920]

Pediatrics AA. American Academy of Pediatrics: Health care supervision for children with Williams syndrome. Pediatrics. 2001; 107:1192-204. [PubMed: 11331709]

Porter MA, Coltheart M, Langdon R. The neuropsychological basis of hypersociability in Williams and Down syndrome. Neuropsychologia. 2007; 45:2839-2849. [PubMed: 17597166]

Reilly, J.; Bernicot, J.; Vicari, S.; Lacroix, A.; Bellugi, U., editors. Narratives in children with Williams syndrome: A cross linguistic perspective. Kluwer; Dordrecht, the Netherlands: 2005a.

Reilly J, Klima ES, Bellugi U. Once more with feeling: affect and language in atypical population. Dev Psychopathol. 1990; 2:367-391.

Reilly J, Lacroix A, Poirier J, Bernicot J, Bellugi U, Klima E. Narratives in French and American Children with Williams Syndrome. L'homme et Langage. Dec.2005b :111-125. 2005. L'homme et Langage. 40:111-125. 111-126.

Reilly J, Losh M, Bellugi U, Wulfeck B. “Frog, where are you?” Narratives in children with specific language impairment, early focal brain injury, and Williams syndrome. Brain Lang. 2004; 88:229247. [PubMed: 14965544]

Reilly JS, Bates EA, Marchman VA. Narrative discourse in children with early focal brain injury. Brain Lang. 1998; 61:335-375. [PubMed: 9570869]

Reiss AL, Eckert MA, Rose FE, Karchemskiy A, Kesler S, Chang M, Reynolds MF, Kwon H, Galaburda A. An experiment of nature: brain anatomy parallels cognition and behavior in Williams syndrome. J Neurosci. 2004; 24:5009-5015. [PubMed: 15163693]

Reiss AL, Eliez S, Schmitt JE, Straus E, Lai Z, Jones W, Bellugi U. IV. Neuroanatomy of Williams syndrome: a high-resolution MRI study. J Cogn Neurosci. 2000; 12(Suppl 1):65-73. [PubMed: 10953234]

Reiss AL, Hennessey JG, Rubin M, Beach L, Abrams MT, Warsofsky IS, Liu AM, Links JM. Reliability and validity of an algorithm for fuzzy tissue segmentation of MRI. J Comput Assist Tomogr. 1998; 22:471-479. [PubMed: 9606391]

Roberts NA, Beer JS, Werner KH, Scabini D, Levens SM, Knight RT, Levenson RW. The impact of orbital prefrontal cortex damage on emotional activation to unanticipated and anticipated acoustic startle stimuli. Cogn Affect Behav Neurosci. 2004; 4:307-316. [PubMed: 15535166]

Salmond CH, Ashburner J, Vargha-Khadem F, Connelly A, Gadian DG, Friston KJ. Distributional assumptions in voxel-based morphometry. Neuroimage. 2002; 17:1027-30. [PubMed: 12377176]

Schmitt JE, Eliez S, Bellugi U, Reiss AL. Analysis of cerebral shape in Williams syndrome. Arch Neurol. 2001a; 58:283-287. [PubMed: 11176967]

Schmitt JE, Eliez S, Warsofsky IS, Bellugi U, Reiss AL. Enlarged cerebellar vermis in Williams syndrome. J Psychiatr Res. 2001b; 35:225-229. [PubMed: 11578640]

Schoenemann PT, Sheehan MJ, Glotzer LD. Prefrontal white matter volume is disproportionately larger in humans than in other primates. Nat Neurosci. 2005; 8:242-52. [PubMed: 15665874] 
Stromme P, Bjornstad PG, Ramstad K. Prevalence estimation of Williams syndrome. J Child Neurol. 2002; 17:269-271. [PubMed: 12088082]

Talairach, J.; Tournoux, P. Co-planar stereotaxic atlas of the human brain. Thieme; New York: 1988.

Thompson PM, Lee AD, Dutton RA, Geaga JA, Hayashi KM, Eckert MA, Bellugi U, Galaburda AM, Korenberg JR, Mills DL, Toga AW, Reiss AL. Abnormal cortical complexity and thickness profiles mapped in Williams syndrome. J Neurosci. 2005; 25:4146-4158. [PubMed: 15843618]

Van Essen DC, Dierker D, Snyder AZ, Raichle ME, Reiss AL, Korenberg J. Symmetry of cortical folding abnormalities in Williams syndrome revealed by surface-based analyses. J Neurosci. 2006; 26:5470-5483. [PubMed: 16707799]

Wechsler, D. Administration and Scoring Manual. Third Edition. The Psychological Corporation; San Antonio, TX: 1997. Wechsler Adult Intelligence Scale.

Zitzer-Comfort C, Doyle TF, Masataka N, Korenberg J, Bellugi U. Nature and nurture: Williams syndrome across cultures. Developmental Science. 2007; 10:755-762. [PubMed: 17973792] 

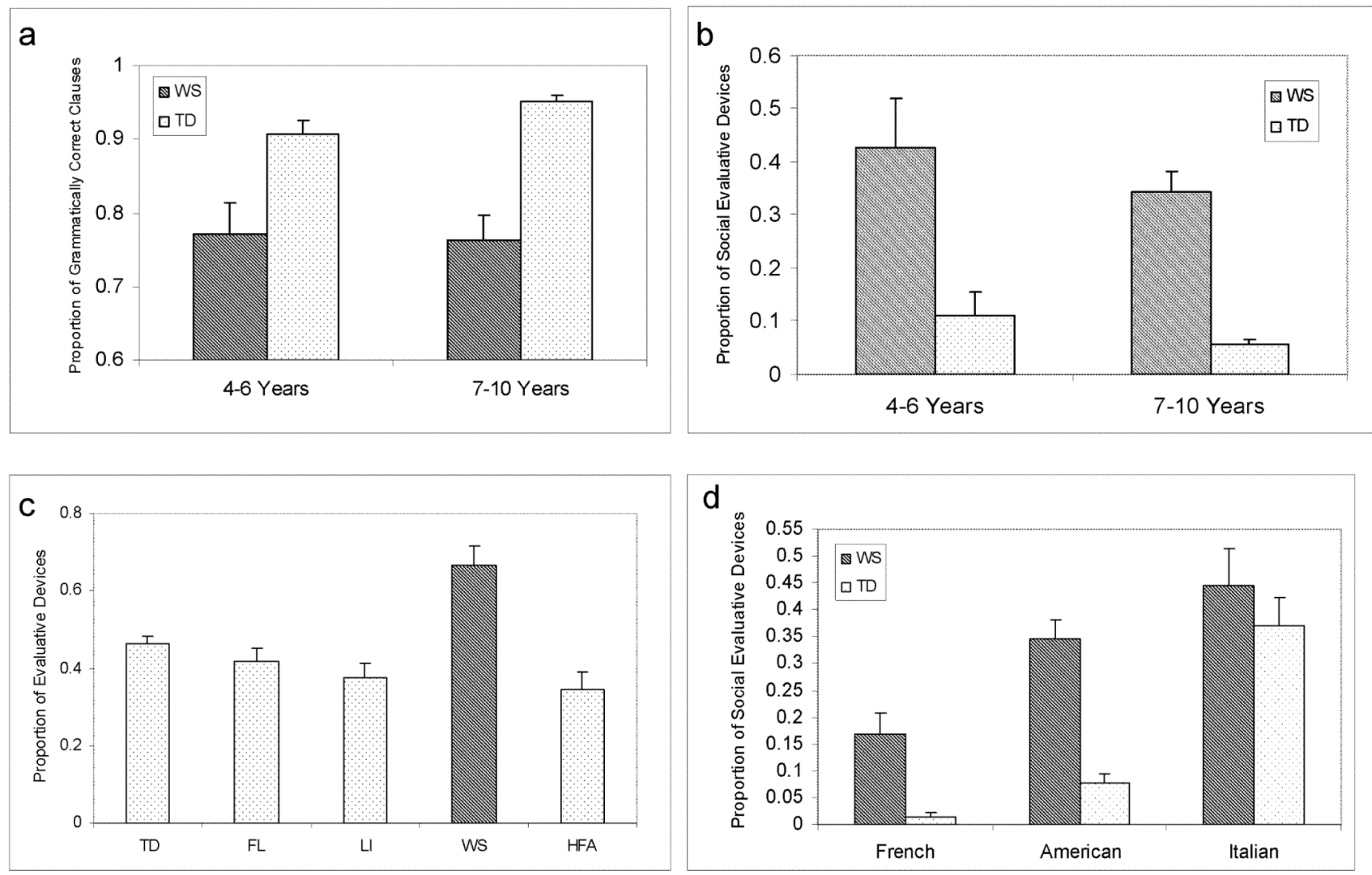

Legend to Figure 1.

In comparison to typically developing controls (TD), WS show grammatical impairment in morphosyntax (Panel 1A), yet exhibit consistently higher use of social affective language (Panel 1B). WS also exhibit significantly higher use of social language than TD subjects, subjects with early focal lesions (FL), language impairment (LI), and high functioning autism (HFA) (Panel 1C). Abnormally high use of social affective language is characteristic in WS compared with normal controls from three different cultures (Panel 1D). Adapted with permission from Reily et al. 2004 and Reily et al. 2005. 

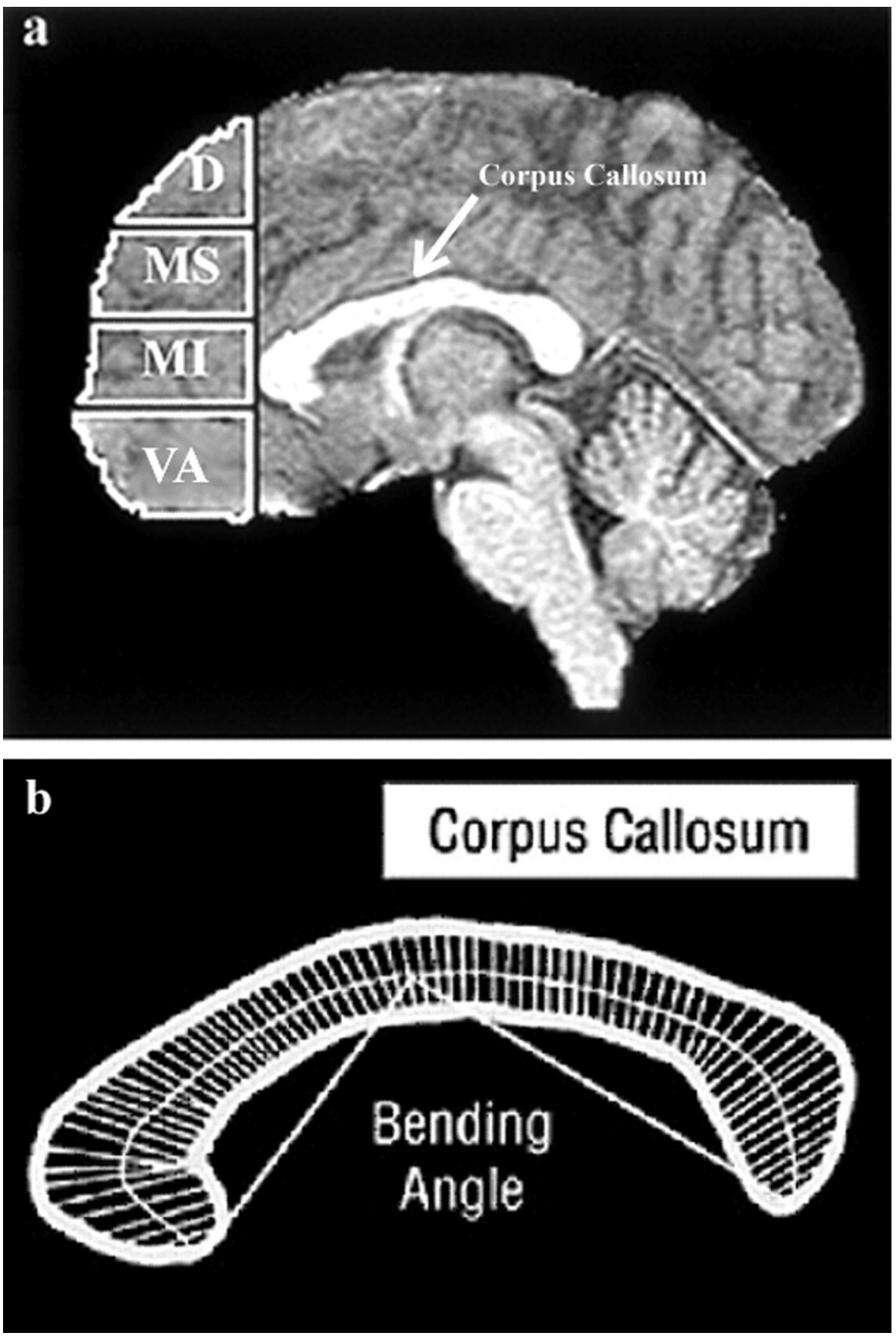

Legend to Figure 2.

Panel A-shows the subdivisions of the prefrontal cortex. The prefrontal cortex was defined as the part of the cortex lying anterior to a coronal plane intersecting the most anterior point of the genu of the corpus callosum. The prefrontal cortex was then subdivided by three axial planes parallel to a line passing through the anterior and posterior commissure. Each axial plane was determined at the same location for each participant after fitting a proportional (Talairach) grid system to the normalized brain. The prefrontal percolation yielded four prefrontal subregions: $\mathrm{D}=$ dorsal, $\mathrm{MS}=$ middle-superior, $\mathrm{MI}=$ middle-inferior, $\mathrm{VA}=$ ventral-anterior. 
Panel B- The bending angle of the corpus callosum is the angle created by lines connecting the most anterior and posterior points of the corpus callosum with the midline of the corpus callosum. 


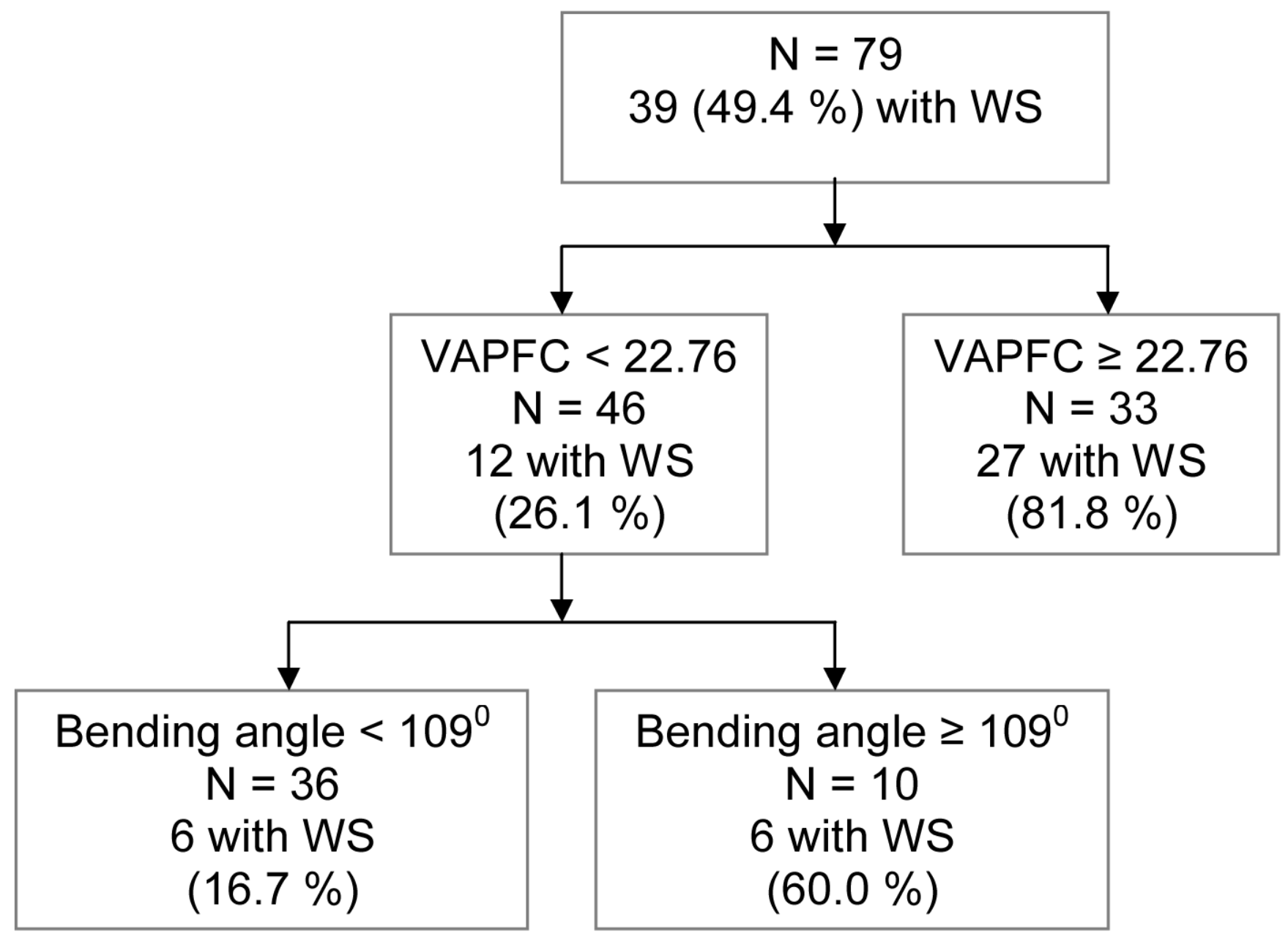

Legend to Figure 3.

Quality receiver operating characteristic curve (QROC) showing the brain regions that best distinguish between subjects with WS and controls. 


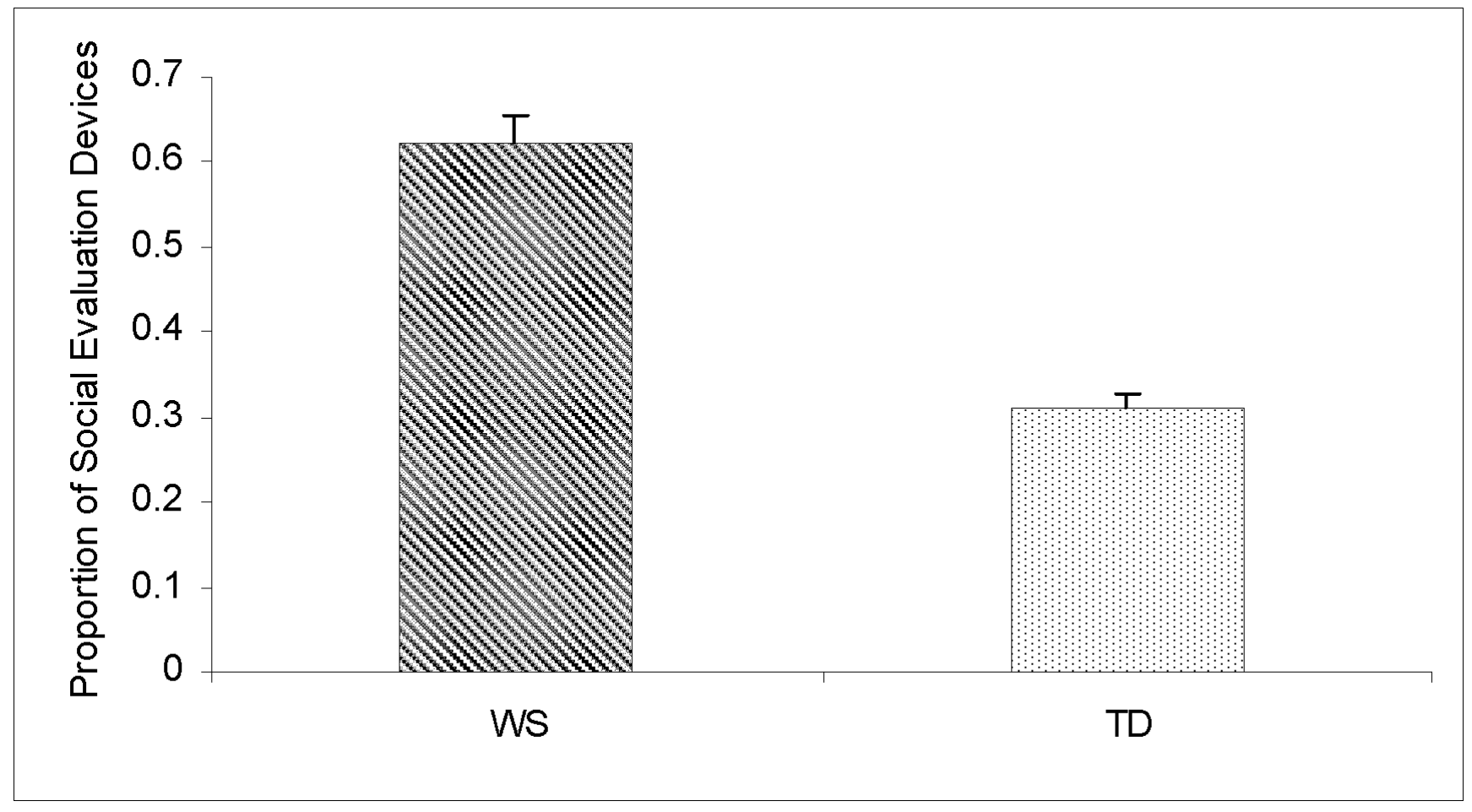

Legend to Figure 4.

Proportion of social evaluation devices (SED) was significantly higher in the Williams syndrome (WS) group compared to typically developing controls (TD). 
Table 1

Clinical Characteristics of Study Subjects

\begin{tabular}{|l|c|c|}
\hline & Williams Syndrome & Controls \\
\hline Mean Age (SD) & $30.3(8.4)$ & $27.5(7.4)$ \\
\hline Males / Females & $18 / 21$ & $16 / 24$ \\
\hline Mean Full-Scale IQ (SD) & $69.6(7.2)$ & \\
\hline Mean Verbal IQ (SD) & $72.8(6.8)$ & \\
\hline Mean Performance IQ (SD) & $68.5(7.7)$ & \\
\hline Mean SED scores (SD) & $0.61(0.17)$ & \\
\hline
\end{tabular}

